\title{
New-graduate physiotherapists' self-efficacy and preparedness for patient education practice: $A$ mixed methods study
}

\author{
S. Wilesmith, A. Yong Yao Lao \& R. Forbes
}

\begin{abstract}
Introduction: Patient education is a fundamental component of effective physiotherapy practice. Current literature suggests that physiotherapists may not be adequately prepared for patient education practice; however, perception of graduate preparedness for professional practice has not been explored. This study aimed to investigate newgraduate physiotherapists' self-efficacy for practising patient education and explore their perceived preparedness for transitioning into this professional role.
\end{abstract}

Methods: This study utilised a sequential mixed-methods design. New-graduate physiotherapists completed the Patient Education Self Efficacy Scale at the conclusion of their pre-professional training $(n=149)$. Following entry to the workforce, $a$ randomised sample of 15 of these individuals participated in semi-structured interviews exploring perceptions and experiences of practising patient education. Interview data were subject to framework analysis.

Results: Highest scoring self-efficacy items were: understanding the role of patient education and questioning to seek the patient's perceptions and concerns about their condition. The lowest scoring item was: recognising and effectively managing barriers to effective education. Five themes emerged: (1) patient education is a powerful tool, (2) individualised education is highly valued, (3) decreased confidence when facing complexity, (4) overcoming patient-related barriers is challenging and (5) practical experience is critical for skill development.

School of Health and Rehabilitation Sciences, The University of Queensland, St Lucia, Australia

\section{Correspondence}

Sarah Wilesmith

Physiotherapist

School of Health and Rehabilitation Sciences

The University of Queensland

St Lucia 4072

Australia

Tel: +61 733652718

Email: sarah.wilesmith@uqconnect.edu.au 
Conclusion: New-graduate physiotherapists demonstrated high self-efficacy and perceived preparedness in most aspects of patient education. Interview findings corroborated survey results indicating that new graduates perceive difficulty in managing barriers to patient education and are challenged when facing complex situations. Direct experience was perceived as the most beneficial for enhancing self-efficacy and preparedness for patient education.

Keywords: physiotherapy; new-graduate; self-efficacy; preparedness; patient education

\section{Introduction}

Patient education is defined as a planned learning intervention aimed at influencing patient knowledge and health behaviours (Bartlett, 1985; Bastable, 2016). Effective patient education has been demonstrated to improve patient self-efficacy (Ndosi et al., 2015; Nour et al., 2006), promote patient self-management (Ndosi et al., 2015; Nunez et al., 2006) and enhance physiotherapy outcomes, including pain, disability and function (Albaladejo et al., 2010; Alston \& O'Sullivan, 2005; Louw et al., 2011). A "patient-centred approach", whereby education is individualised to the patient's learning needs, has been strongly advocated as best practice in recent healthcare literature (Cheng et al., 2016; Epstein \& Street, 2011; Pinto et al., 2012). Physiotherapists accrue greater patient contact time across longer clinical episodes than other health professionals (Ross \& Haidet, 2011) and are, thus, well situated to deliver individualised education in a diverse range of healthcare settings (Davis \& Chesbro, 2003; Jette et al., 2005). Recent evidence emphasises the prevalence of education within the physiotherapy profession, suggesting that up to $30 \%$ of consultation time is dedicated explicitly to education (Forbes, Mandrusiak, Russell, \& Smith, 2017). Accordingly, competency in patient education is required for entry-level physiotherapy practice in many countries, including Australia, New Zealand and North America (APTA, 2016; PBA and PBNZ, 2015), and training institutions are responsible for ensuring graduates enter the workforce with competency in this area of practice. Training varies between institutions and may involve a combination of didactic teaching, case-based learning, simulated patient scenarios and practical experience during clinical placements (Forbes, 2017).

A review of the literature highlights concerns with how physiotherapists implement patient education in clinical practice. Research has demonstrated that physiotherapists without formal training in patient education tend to be guided by personal experience (Forbes, Mandrusiak, Smith, \& Russell, 2017), rather than evidence-based practice (Jette et al., 2005; Svavarsdóttir et al., 2015), and exhibit a predominantly therapistcentered and didactic education approach, which is seldom individualised to the patient (Hiller et al., 2015; Kerssens et al., 1999). Additionally, physiotherapists may use patient education less often than guidelines advise (Jette et al., 2005) and can perceive challenges with specific aspects of patient education, including effectively explaining diagnostic information or symptoms for common clinical conditions (Slade et al., 2012). These concerns are especially evident during patient education interventions practised by inexperienced physiotherapists (Forbes, Mandrusiak, Smith, \& Russell, 2017; Jensen, Gwyer, et al., 2000; Resnick \& Jensen, 2003). Early research 
shows that novice and student physiotherapists prioritise other clinical interventions over patient education (Holmes, 1999; Jensen, Shepard, \& Hack, 1990). Additionally, Holmes (1999) determined that student physiotherapists perceived themselves to have a lower ability to individualise education and identified a greater number of barriers to education than practising therapists. Research by Forbes, Mandrusiak, Smith and Russell (2017) corroborated these earlier findings using a wide-scale survey, which found that novice physiotherapists perceive more barriers to education and self-report a lower use of patient-centered techniques compared to their experienced colleagues. Svavarsdóttir et al. (2016) also found that novice health professionals, including physiotherapists, are proficient in delivery of information but encounter difficulty in prioritising appropriate educational content or individualising health-related education to the patient.

Self-efficacy, an individual's perception of their ability to perform a task or behavior (Bandura, 1977), is an important paradigm in understanding how health professionals engage in professional practice, as it influences motivation and skill attainment and is predictive of clinical performance (Jones \& Sheppard, 2011). Low self-efficacy has been shown to negatively impact patient education provided by student and graduate health professionals (Darkwah et al., 2011; Svavarsdóttir et al., 2015), including physiotherapists (Forbes et al., 2018b). Almost all current literature relating to patient education practice in physiotherapy and wider health professions consists of self-report surveys. Consequently, very little research to date has explored physiotherapist selfefficacy in practising patient education or what influences their preparedness for practice. There has been no research specifically investigating the preparedness of new-graduate physiotherapists to practise patient education, demonstrating a gap in understanding with regards to how graduate therapists transition from pre-professional training into clinical practice and how best to prepare them. The aim of this mixed-methods study was to: 1) examine the self-efficacy of new-graduate physiotherapists in professional practice of patient education and 2) explore the influence of pre-professional training and early work experience on perceived preparedness of new graduates for transition into this professional role.

\section{Methods}

\section{Design}

This study utilised an explanatory sequential mixed-methods research design, selected to facilitate a thorough exploration of the research aims through synthesis of both measurable and explorative data (Creswell, 2014). The initial quantitative crosssectional self-report survey aimed to examine new-graduate physiotherapist self-efficacy in relation to patient education competencies specific to physiotherapy practice. The subsequent qualitative descriptive phase used in-depth semi-structured interviews (Moustakas, 1994) to further explore self-efficacy and perceived preparedness of new graduates following their entry into the workforce and the influence of pre-professional training experiences. Investigator triangulation was implemented to enhance validity and credibility of results (Mays \& Pope, 2000). Ethical clearance for this study was gained from The University of Queensland-Institutional Human Research Ethics approval number 2009001668. 


\section{Measurement instruments}

\section{Survey}

The self-report Patient Education Self Efficacy Scale (PESES) (Forbes et al., 2018b) was used to measure new-graduate physiotherapist self-efficacy for patient education practice. The PESES is a previously published 21-item scale, developed specifically for use in physiotherapy practice through expert consensus on graduate-level physiotherapy patient education requirements. The measure demonstrates an interrater reliability of 0.76 and internal consistency of 0.81 in a final-year physiotherapy student population (Forbes et al., 2018b). Demographic questions were incorporated within the same survey measure and included age, gender and type of professional education program undertaken. A separate form requesting consent to be contacted for the semi-structured interviews the following year was included.

\section{Interviews}

A semi-structured interview framework (Table 1), featuring open-ended questions and probing cues, was developed to explore new-graduate perceptions and experiences. The framework was designed by the research team to expand on PESES survey scale items. Thus, it followed a combined inductive and deductive approach to prompt discussion around thoughts and experiences of patient education in a professional clinical setting and focused on constructs of self-efficacy and preparedness.

\section{Table 1}

Interview Guide and Probing Questions Used During Semi-Structured Interviews

\begin{tabular}{l}
\hline Interview Guide \\
\hline Definition of patient education provided \\
\hline Can you tell me about the role that patient education plays in your typical workday? \\
\hline When you consider all the management modalities available to you, can you explain where patient education falls as a \\
priority? \\
\hline Tell me about what effective patient education means for you as a therapist. \\
\hline Can you describe situations where you feel confident in practising patient education? \\
\hline Can you describe situations where patient education is required where you feel you lack readiness? \\
\hline Are there any barriers to providing effective patient education? What are they? \\
\hline Whan you describe your experiences with overcoming barriers to practising patient education? \\
\hline Probing questions \\
Elaboration probes: \\
What do you think helped you to become competent or confident in that area? \\
How did your professional training prepare you for that? \\
How could your training have been altered to improve your competency in practice? \\
\hline Echo probes: \\
You said that you feel confident/competent to do this. Why do you feel this way? \\
You said that you felt unprepared for this. What might have assisted you to feel more prepared? \\
\hline
\end{tabular}




\section{Participants and procedure}

\section{Survey}

A convenience sample of 151 new-graduate physiotherapists were recruited in person from a single Australian tertiary institution at the conclusion of their professional training program (Figure 1). Inclusion was limited to individuals who had successfully fulfilled requirements for graduation from a 4-year full-time bachelor-entry program or 2-year full-time equivalent master's-entry program.

Participants were invited to complete an anonymous 10-minute hardcopy survey and separate interview recruitment form during an on-campus end-of-year meeting at the completion of their studies. This process was overseen by a university staff member independent to the study, who was also responsible for distributing and collecting all forms.

\section{Interviews}

Inclusion for interview participation was limited to individuals undertaking full-time or part-time work as a physiotherapist in a clinical setting. Individuals who consented to be contacted were arbitrarily assigned a number, and a computerised random number generator determined the order in which participants were sequentially contacted via email to request participation. Telephone interviews were scheduled based on participant nominated availability by return email. If no response was received within 7 days, random selection continued. This process was terminated when concurrent framework analysis determined data saturation was reached.

Interviews were conducted by telephone from April to June 2019 (Figure 1) by the lead researcher (SW) in order to access a geographically dispersed sample. The interview framework was implemented throughout, and probes were used where necessary to clarify and explore responses (Table 1). Interviews were recorded via smartphone and transcribed verbatim with concurrent framework analysis based on PESES items, which reflect known competencies for patient education (Forbes et al., 2018a, 2018b). Accompanying field notes summarised researcher insights. Interviews were discontinued after data saturation was reached and no new codes or themes emerged.

\section{Figure 1}

\section{Data Collection Timeline}

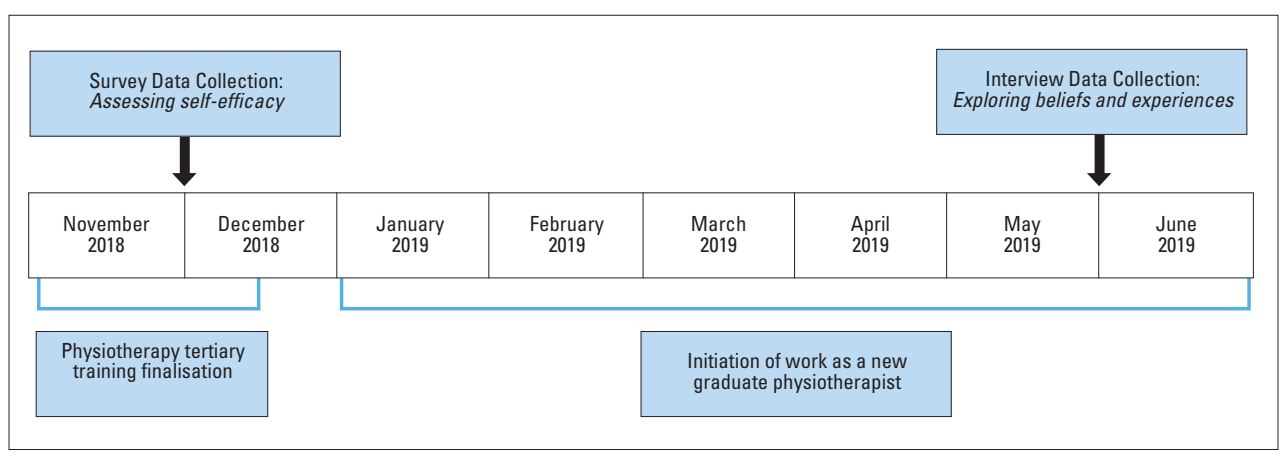




\section{Data analysis}

Survey data were manually entered into Microsoft Excel Version 2016 and checked for missing responses. Microsoft Excel was used to generate descriptive statistics of demographic information (Table 2) and frequency distributions for self-efficacy survey items (Table 3). Statistical analysis of quantitative data was conducted using SPSS Version 20.0. A Mann-Whitney $U$ test was used to compare self-efficacy survey scores according to gender or program of study. Significance was set at $p=<0.05$.

Interview data were subjected to a framework method of analysis to generate descriptive conclusions centred on themes using a combined deductive and inductive approach to determine connections with quantitative data and explore new findings (Moustakas, 1994). A thematic framework was developed using a priori codes based on responses to PESES items to facilitate deductive analysis and ensure interview responses would inform survey data.

Data analysis was commenced after the first interview and continued concurrently with subsequent interviews. During the transcription and familiarisation phases of analysis, the principle researcher $(\mathrm{SW})$ reviewed interview transcripts multiple times to become sensitised to the data (Creswell, 2014). Transcripts were subsequently coded deductively and inductively to reflect experiences described by participants. Similar codes were grouped to form subcategories. Codes and subcategories were subject to continuous comparison and differentiation as new data emerged with ongoing interviews. Final coding involved mapping interrelationships and associations between subcategories and determining the main themes that encompassed the subcategories.

The lead researcher (SW) undertook a process of epoché by noting beliefs and opinions relevant to the phenomenon. This process was conducted separately by the third researcher $(\mathrm{RF})$, and all coding was subsequently compared and refined to enhance credibility and validity of study results through data triangulation (Mays \& Pope, 2000).

The research team met regularly to implement ongoing data triangulation and resolve inconsistencies in interpretation of data, ensuring rigour and reflexivity. Effort was taken to minimise bias by ensuring interview participants were not personally known to the interviewer and that personal interview questions were avoided. Additional strategies were implemented to assist with verification and trustworthiness of the generated data. Two new-graduate physiotherapists were consulted to evaluate appropriateness of data interpretation and two practising physiotherapists were consulted to critique themes, codes and illustrative quotes.

\section{Results}

\section{Patient education self-efficacy survey}

A total of 149 participants completed the survey (response rate 149/151, 98.68\%). Participant demographics are outlined in Table 2. A total of 47 respondents $(31.54 \%)$ selected "agree" or "strongly agree" for all survey items. Only nine respondents $(6.04 \%)$ selected "disagree" for at least one item. The two items with the highest self-efficacy 
scores, in which over 95\% respondents selected "agree" or "strongly agree" were: I understand the role of patient education $(\mathrm{n}=149,100 \%)$ and I feel confident to use questioning to seek the patient's perceptions and concerns about their condition ( $\mathrm{n}=143$, 95.97\%). Eight other survey items featured response rates of over $90 \%$ for "agree" or "strongly agree". The item with the lowest self-efficacy score, indicated by the greatest proportion of respondents selecting "strongly disagree", "disagree" or "undecided", was I feel confident to recognise and effectively manage barriers to effective education ( $\mathrm{n}=40$, $26.85 \%)$. There were no statistically significant differences between individual survey item scores based on gender $(p=0.09-0.94)$ or program of study $(p=0.08-0.65)$. All self-efficacy survey results are outlined in Table 3.

Table 2

Subject Demographic Information

\begin{tabular}{l|c|c}
\hline & $\begin{array}{c}\text { Survey Respondents } \\
(\mathrm{n}=149)\end{array}$ & $\begin{array}{c}\text { Interview Participants } \\
(\mathrm{n}=15)\end{array}$ \\
\hline Age, mean years & 23.8 & 24.1 \\
\hline Gender, $\mathbf{n}(\%)$ & $94(63.1 \%)$ & $10(66.7 \%)$ \\
$\quad$ Female & $55(34.9 \%)$ & $5(33.3 \%)$ \\
$\quad$ Male & $112(75.2 \%)$ & $13(86.7 \%)$ \\
\hline Physiotherapy degree, $\mathbf{n}(\%)$ & $37(24.8 \%)$ & $2(13.3 \%)$ \\
$\quad$ Bachelor entry & & $4(26.7)$ \\
Master's entry & & $3(20.0)$ \\
\hline Discipline of practice, $\mathbf{n}(\%)$ & & $8(53.3)$ \\
Public hospital & & $14 \quad(93.3)$ \\
Private hospital & & $1(6.7)$ \\
Private practice & & \\
\hline Employment status, $\mathbf{n}(\%)$ & & \\
Full time & & \\
Part time & & \\
\hline
\end{tabular}

\section{Semi-structured interviews}

Seventy-nine individuals provided written consent to be contacted for interviewing (response rate $=52.3 \%$ ), and a total of 15 semi-structured telephone interviews were conducted from April to June 2019. Interviews ranged from 18 to 41 minutes (mean $=24$ minutes). Participants had a mean age of 24.13 years (range 22 to 38 years), the majority were female $(n=10,66.7 \%)$ and from the bachelor's-entry program $(\mathrm{n}=13,86.7 \%)$. Most participants were employed full time within public hospitals $(\mathrm{n}=4,26.6 \%)$, private hospitals $(\mathrm{n}=3,20.0 \%)$ or private practice settings $(\mathrm{n}=5$, $33.3 \%$ ). Further demographic information is outlined in Table 2 and Table 4. Five final themes emerged from the interview data following analysis: (1) patient education is a powerful tool, (2) individualised education is highly valued, (3) decreased confidence when facing complexity, (4) overcoming patient-related barriers is challenging and (5) practical experience is critical for skill development. 


\section{Table 3}

Frequencies of Patient Education Self-Efficacy Survey Scores

\begin{tabular}{|c|c|c|c|c|c|}
\hline Survey Item (Competencies) & $\begin{array}{c}\text { Strongly } \\
\text { Disagree } \\
\mathrm{n}(\%)\end{array}$ & $\begin{array}{c}\text { Disagree } \\
n(\%)\end{array}$ & $\begin{array}{l}\text { Undecided } \\
\qquad \mathrm{n}(\%)\end{array}$ & $\begin{array}{l}\text { Agree } \\
\mathrm{n}(\%)\end{array}$ & $\begin{array}{l}\text { Strongly } \\
\text { Agree } \\
\mathrm{n}(\%)\end{array}$ \\
\hline $\begin{array}{l}\text { 1. I understand the role of patient } \\
\text { education }\end{array}$ & $0(0.0)$ & $0(0.0)$ & $0(0.0)$ & $49(33.0)$ & $100(67.1)$ \\
\hline $\begin{array}{l}\text { 2. I understand the impact of social, } \\
\text { cultural and behavioural variables } \\
\text { on patient learning }\end{array}$ & $0(0.0)$ & $2(1.3)$ & $12(8.1)$ & $92(61.7)$ & $43(28.9)$ \\
\hline $\begin{array}{l}\text { 3. I understand the principles of adult } \\
\text { learning }\end{array}$ & $0(0.0)$ & $1(0.7)$ & $24(16.1)$ & $72(48.3)$ & $52(34.9)$ \\
\hline $\begin{array}{l}\text { 4. I feel confident to use questioning } \\
\text { to seek the patient's perceptions } \\
\text { and concerns about their condition }\end{array}$ & $0(0.0)$ & $0(0.0)$ & $6(4.0)$ & $70(47.0)$ & $73(49.0)$ \\
\hline $\begin{array}{l}\text { 5. ... to obtain information from the } \\
\text { patient assessment to understand } \\
\text { their learning needs }\end{array}$ & $0(0.0)$ & $0(0.0)$ & $9(6.0)$ & $97(65.1)$ & $43(28.9)$ \\
\hline $\begin{array}{l}\text { 6. ... to use reflective questioning } \\
\text { (questions that allow the patient to } \\
\text { reflect out loud) }\end{array}$ & $0(0.0)$ & $1(0.7)$ & $28(18.8)$ & $76(51.0)$ & $44(29.5)$ \\
\hline $\begin{array}{l}\text { 7. ... to select and use a range of } \\
\text { appropriate learning content } \\
\text { tailored to the patient }\end{array}$ & $0(0.0)$ & $0(0.0)$ & $22(14.8)$ & $91(61.1)$ & $36(24.2)$ \\
\hline $\begin{array}{l}\text { 8. ... to explain the patient's } \\
\text { condition to them }\end{array}$ & $0(0.0)$ & $1(0.7)$ & $32(21.5)$ & $91(61.1)$ & $25(16.8)$ \\
\hline 9. ... to use shared decision making & $0(0.0)$ & $0(0.0)$ & $19(12.8)$ & $100(67.1)$ & $30(20.1)$ \\
\hline $\begin{array}{l}\text { 10.... to provide self-management } \\
\text { strategies to the patient and } \\
\text { reinforce their ability to manage }\end{array}$ & $0(0.0)$ & $1(0.7)$ & $24(16.1)$ & 89 (59.7) & 35 (23.5) \\
\hline $\begin{array}{l}11 \ldots \text { to provide family or caregivers } \\
\text { with information (where they } \\
\text { are present) }\end{array}$ & $0(0.0)$ & $1(0.7)$ & $27(18.1)$ & $88(59.06)$ & $33(22.2)$ \\
\hline $\begin{array}{l}\text { 12.... to tailor communication styles, } \\
\text { languages and materials to the } \\
\text { patient }\end{array}$ & $0(0.0)$ & $1(0.7)$ & $29(19.5)$ & $91(61.1)$ & $28(18.8)$ \\
\hline $\begin{array}{l}\text { 13.... to control attention and } \\
\text { engagement when educating the } \\
\text { patient }\end{array}$ & $0(0.0)$ & $0(0.0)$ & $16(10.7)$ & $100(67.1)$ & $33(22.2)$ \\
\hline $\begin{array}{l}14 \ldots \text { to provide education content } \\
\text { that is in the best interests of the } \\
\text { patient }\end{array}$ & $0(0.0)$ & $3(2.0)$ & 20 (13.4) & 76 (51.0) & 50 (33.6) \\
\hline $\begin{array}{l}15 . . . \text { to recognise and effectively } \\
\text { manage barriers to effective } \\
\text { education }\end{array}$ & $0(0.0)$ & $1(0.7)$ & 39 (26.2) & $86(57.7)$ & $23(15.4)$ \\
\hline $\begin{array}{l}\text { 16.... to summarise information for } \\
\text { the patient }\end{array}$ & $0(0.0)$ & $0(0.0)$ & $10(6.7)$ & 94 (63.1) & $45(30.2)$ \\
\hline
\end{tabular}




\section{Table 3}

Frequencies of Patient Education Self-Efficacy Survey Scores (contd.)

\begin{tabular}{|c|c|c|c|c|c|}
\hline Survey Item (Competencies) & $\begin{array}{c}\text { Strongly } \\
\text { Disagree } \\
\mathrm{n}(\%)\end{array}$ & $\begin{array}{c}\text { Disagree } \\
n(\%)\end{array}$ & $\begin{array}{c}\text { Undecided } \\
\mathrm{n}(\%)\end{array}$ & $\begin{array}{l}\text { Agree } \\
n(\%)\end{array}$ & $\begin{array}{c}\text { Strongly } \\
\text { Agree } \\
\mathrm{n}(\%)\end{array}$ \\
\hline $\begin{array}{l}17 \ldots \text { to integrate evidence-based } \\
\text { practice into patient education }\end{array}$ & $0(0.0)$ & $0(0.0)$ & $36(24.2)$ & $86(57.7)$ & $27(18.1)$ \\
\hline $\begin{array}{l}\text { 18.... to identify when patient learning } \\
\text { has been achieved through } \\
\text { evaluation }\end{array}$ & $0(0.0)$ & $1(0.7)$ & $10(6.7)$ & $93(62.4)$ & $45(30.2)$ \\
\hline $\begin{array}{l}\text { 19.... to review progress of the } \\
\text { patient's learning }\end{array}$ & $0(0.0)$ & $0(0.0)$ & $9(6.0)$ & $89(59.7)$ & $51(34.2)$ \\
\hline $\begin{array}{l}\text { 20.... to provide patient education } \\
\text { within the limits of my practice and } \\
\text { refer on to another professional } \\
\text { where appropriate }\end{array}$ & $0(0.0)$ & $0(0.0)$ & $8(5.4)$ & $96(64.4)$ & $45(30.2)$ \\
\hline $\begin{array}{l}21 \ldots \text { to take action to continue to } \\
\text { develop my patient's education } \\
\text { skills (professional development) }\end{array}$ & $0(0.0)$ & $0(0.0)$ & $10(6.7)$ & $77(51.7)$ & $62(41.6)$ \\
\hline
\end{tabular}

\section{Table 4}

De-identified Interview Participant Details

\begin{tabular}{c|c|c|c|c|c}
\hline $\begin{array}{c}\text { Subject } \\
\text { Number }\end{array}$ & Age (years) & Gender & $\begin{array}{c}\text { Bachelor's/ } \\
\text { Master's Entry }\end{array}$ & $\begin{array}{c}\text { Discipline of Work } \\
\text { as New Graduate }\end{array}$ & $\begin{array}{c}\text { Full Time/ } \\
\text { Part Time }\end{array}$ \\
\hline P1 & 27 & Male & ME & Private practice & FT \\
\hline P2 & 22 & Female & BE & Public hospital & FT \\
\hline P3 & 38 & Male & ME & Private practice & FT \\
\hline P4 & 22 & Female & BE & Private hospital & PT \\
\hline P5 & 23 & Female & BE & Private practice & FT \\
\hline P6 & 23 & Female & BE & Private practice & FT \\
\hline P7 & 22 & Female & BE & Private hospital & FT \\
\hline P8 & 23 & Male & BE & Private practice & FT \\
\hline P9 & 22 & Female & BE & Private practice & FT \\
\hline P10 & 26 & Male & BE & Private practice & FT \\
\hline P11 & 23 & Male & BE & Public hospital & FT \\
\hline P12 & 22 & Female & BE & Private practice & FT \\
\hline P13 & 22 & Female & BE & Private hospital & FT \\
\hline P14 & 22 & Female & BE & Public hospital & FT \\
\hline P15 & 25 & Female & BE & Public hospital & FT \\
\hline
\end{tabular}

Abbreviations: $\mathrm{BE}=$ bachelor entry; $\mathrm{ME}=$ master's entry; $\mathrm{FT}$ = full time; $\mathrm{PT}=$ part time 


\section{(1) Patient education is a powerful tool}

Patient education was unanimously regarded as a crucial aspect of participants' selfperceived capacity to support patients in achieving healthcare outcomes.

It's basically the bulk of treatment ... health literacy can be one of the limiting factors to people getting better or doing the right thing to get better. (P15)

This perspective appeared to be centered around participants' perception that education is invaluable for empowering patients towards proactive self-management and shifting the locus of control to the patient.

Being able to educate [patients] to do the right thing in the majority of time when they're going to be alone; it's when they're going to do most of their rehab. (P14)

If you can give them something that they can apply outside of the sessions, it's going to be really useful. (P6)

All participants emphasised that they prioritise education highly in relation to other physiotherapy management modalities, further explaining that they believe education enhances the patient-therapist relationship by engendering rapport and trust, subsequently improving therapeutic compliance.

That's really important for the patient's own self-efficacy, actually knowing what's going on, being confident in what's going on so they can actually progress with us. (P11)

I think if they don't have an understanding of why they have to do things, and what the consequences and effects are, then they're much less likely to do them. (P4)

Entry-level training was perceived as playing a powerful role in shaping participant opinions regarding the clinical significance of education interventions.

As the course progressed, I think the value of advice and education became more and more emphasised. (P11)

Additionally, curriculum-based teaching directly guided graduate prioritisation and use of education upon transition to professional practice.

You learned that patient education can be your main treatment. (P4)

(2) Individualised education is highly valued

Participants conveyed that in every instance, tailoring education content to patient needs and motivations was a strong focus within their clinical practice.

I try and make [education] specific to the patient ... make it relevant to them and what they enjoy or what their work is. (P4)

It depends on the patient... if they've got yellow flags, I'll try to prioritise patient education more to try to avoid the chronic pain processing happening, or try to change to some more positive behaviours. (P8) 
Several participants expressed the view that individualisation of education delivery approaches was essential to the efficacy and success of that intervention.

Taking what I've been taught as a student, very anatomical language and scientific, and putting that into something they understand... if you give them education in words they don't understand, then it's not going to help them at all. (P14)

In addition to needs and motivations, participants discussed how patient expectations strongly influence their prioritisation and implementation of education with respect to other management strategies.

For patients who are more interested in self-management, then I'll provide more patient education. Whereas [for] patients who prefer passive treatments ... that wouldn't be the focus of my consult. (P5)

One participant strongly emphasised that patient expectations were the most important factor dictating treatment decisions.

Patients come in to be touched. So if you don't lay a hand on them, it doesn't matter what you say, it's not going to be worth them coming in, they won't come back. (P1)

\section{(3) Decreased confidence when facing complexity}

Perceived complexity was a key source of apprehension and challenge for participants when delivering patient education.

While I am confident in doing like the standard stuff, some patients ask me questions that are a bit out of the box... then I'm not really confident to give a good answer because I know that it's probably wrong. (P2)

Participants described lacking a sense of preparedness and confidence to overcome uncertainty or complexity.

When a patient asks difficult questions... if they ask me something that I'm not really sure about, I find it a bit more challenging to provide patient education with more confidence. (P5)

If I'm not quite sure what it is I'm doing, it's obviously pretty hard to get that across confidently if I'm not even sure what I'm saying. (P3)

They often recounted examples that they found challenging.

Having to try and explain activities that aren't so good for kids, or a child that has a progressive condition that will get worse. Trying to find a balance of how much I tell them, how much they already know. (P9)

The source of decreased confidence was often attributed to feelings of inadequacy relating to their clinical knowledge.

I don't always feel confident in the content, but I always feel confident delivering the content I do know. (P4)

Building or maintaining professional confidence was identified as an important strategy in successful patient education delivery. 
I think self-confidence is a big one, knowing that you're equipped with the knowledge... and then having the self-confidence that you're doing the right thing. (P13)

You've got to sound confident in what you're saying, otherwise they're probably not going to come back. (P10)

\section{(4) Overcoming patient-related barriers is challenging}

Several participants expressed challenges related to managing patient education barriers that were considered to be external to the therapist's locus of control. Participants described situations and difficulties predominantly related to patient factors, such as defensive or challenging communication styles, firmly established health beliefs or behaviours, a passive approach to therapy or altered cognition levels.

They've had it drilled into them for so long that they've had this disc problem, that if a young therapist like myself says, "Oh no, that's completely normal"... they sort of develop a negative attitude towards you straight away. (P10)

Demented patients or people that lack insight-it can be really tough. I know you can't always do anything about that ... because they're not really understanding, it can be really difficult to be effective. (P15)

On further probing, participants explained that many situations were largely out of their ability to control or influence.

There are some times where I've tried literally everything that I've personally experienced for the patient and like they're non-compliant, or they just can't see how it's going to help them. Or they just think they know best. (P7)

Participants outlined that they felt prepared to deliver the patient education but lacked the confidence that their skills would be effective when faced with patient-related barriers.

It's not that I am scared about doing that sort of thing because I feel I can't do it. But it's just that I know that even if I try, it's probably not going to be effective. (P2)

The consensus amongst participants who expressed challenges in this area was that a plateau exists, whereby no amount of skill or preparedness would allow the therapist to be effective.

Some patients, when you're trying to explain quite complex things... they can't really grasp the understanding of that, no matter how you explain it. (P14)

All you can do in the end is ... give your education and do the best you can and then you've just got to walk away really. Some people are just never going to be receptive. (P2)

(5) Practical experience is crucial for skill development

All participants described direct clinical experiences as their most valuable source of patient education skill acquisition and preparedness. Theoretical pre-professional training was identified as central to developing an essential foundation for patient education skills; however, practice-based learning experiences were necessary to establish competency. 
[Theoretical training] did make me confident about patient education, but sometimes in the way it's taught... it's easier to say to us, "This is what you should say to patients", but then when a patient comes in, it's a lot different, because it's like the real person now. (P10)

The main confidence is when you're actually out there in the real world. (P12)

Participants explained that while they felt the clinical learning experiences provided in their pre-professional program were helpful, a more diverse and extensive range of experiences would have better prepared them for new-graduate professional practice.

There's certainly a specific quality you can get to with placement, particularly because they often hand pick you patients and give you the simple ones, and shield you from the complex cases. (P2)

I didn't have a placement in cardiac surgery, and so I really didn't have almost any experience in this kind of workplace, so having no experience that made me initially not very confident. (P2)

Vicarious exposure through observation and collaboration with work colleagues was also fundamental to development of self-efficacy in participants.

You do pick up skills and strategies from the other physios as well. It's just a big combination of all those things. (P13)

More and more practice engaging with real patients is definitely the strongest way to improve skills and the confidence in those skills. (P13)

\section{Discussion}

The overall findings from this study demonstrate that while new graduates possess high self-efficacy and perceived preparedness for most aspects of patient education, they experience difficulties in overcoming barriers to patient education and are challenged when delivering patient education in complex situations. Consistent with previous research, this suggests that graduate physiotherapists may be insufficiently prepared by their entry-level training to meet all competencies required for effective patient education practice (Forbes, Mandrusiak, Smith, \& Russell, 2017). Our findings highlight the importance of direct practice and clinical experiences for developing graduate self-efficacy and preparedness to perform patient education, indicating further areas for improvement in physiotherapy training curricula.

The findings of this research highlight that new-graduate physiotherapists strive to individualise content and delivery of educational interventions, placing a strong emphasis on the implications of patient needs, concerns and expectations. Consideration of the patient's perspective is considered fundamental to patient-centred care (Little et al., 2001; Sanders et al., 2013), as outlined extensively within patient education literature (Forbes et al., 2018a; Skelton, 2001). Although the findings support that new graduates have high self-efficacy in providing patient-centred approaches to education and view it as important, previous literature has indicated that novice therapists have a lower use of patient-centred approaches when compared to their experienced colleagues (Forbes, 
Mandrusiak, Smith, \& Russell, 2017; Svavarsdóttir et al., 2016). The findings may, therefore, indicate an "intention-behaviour gap" (Ajzen, 1991), where although novice therapists perceive patient-centred approaches to be important and feel confident to deliver them, it may not reflect their actual practice.

Delivery of patient-centred care relies heavily on the partnership between the patient and professional in order to facilitate mutual decisions regarding management (Gould \& Mitty, 2010; Hyrkas \& Wiggins, 2014). The results demonstrate that new graduates emphasise the importance of fostering patient rapport and trust through education and, thus, recognise the patient-therapist relationship as critical in providing effective education (Lagger et al., 2010). Pre-professional training was attributed by new graduates in this study as playing a powerful role in shaping their perception of the importance of and use of patient education, supporting that training is integral to promoting patient-centred care in novice physiotherapists (Forbes, Mandrusiak, Smith, \& Russell, 2017, 2018b). Explicit and formalised training of skills that allow health professionals to provide patient-centred care is strongly advocated within the literature (Dwamena et al., 2012; King \& Hoppe, 2013; Levinson et al., 2010); however, this body of research has largely concentrated on communication skills. While initial research has demonstrated enhanced student self-efficacy and performance of patient education skills in physiotherapy student settings (Forbes et al., 2018c), future research is warranted to understand how training can impact actual clinical practice of physiotherapy professionals.

Whilst the majority of new graduates reported high self-efficacy in most areas of patient education, one quarter of survey respondents reported that they were not confident in their ability to recognise or manage barriers to effective education. Interviews strongly corroborated these findings, identifying and describing a range of perceived barriers impeding practice. The perception of barriers in patient education has previously been shown to negatively impact therapist engagement in this area of practice (Sluijs et al., 1993) and may directly influence an individual's reasoning regarding the costs and benefits of a planned action (Glanz et al., 2008). Understanding barriers to effective practice is, therefore, central to understanding therapist behaviour and motivations. In the current study, new graduates specifically identified challenges in overcoming patient-related barriers, including difficulty managing defensive patient communication styles, impaired patient cognition, firmly established, unhelpful patient health beliefs and passive behaviours. This finding is consistent with previous literature, in which physiotherapists reported that they struggle to identify and address psychosocial issues of patients, including unrealistic patient expectations, negative patient emotional responses and pre-existing health beliefs (Sanders et al., 2013). More recent research has similarly indicated that novice physiotherapists have a lower perceived ability to identify and address patient-related barriers than their experienced colleagues, who are better able to control the clinical settings to focus on the patient and their educational goals (Forbes, Mandrusiak, Smith, \& Russell, 2017; Svavarsdóttir et al., 2016). The findings of this study similarly suggest that new-graduate physiotherapists view the 
patient's presentation as a strong determinant to the success of their patient education practice. These results support the assertion that training aimed specifically at building practical skills and self-efficacy to identify and overcome patient-related barriers is warranted (Forbes et al., 2018c).

Physiotherapy education providers are responsible for ensuring graduates are competent for professional practice; however, transferring skills and patient-centred approaches from healthcare education into clinical practice is challenging (Hojat et al., 2009). The findings of this study demonstrate the perceived value of experiential learning and clinical experiences from the perspective of new graduates. They also identified the value of program curricula activities during and prior to clinical placements, in which new graduates were provided with opportunities for direct mastery and observational learning through real practice. Experiential learning and simulation are strongly advocated within health educational literature (Dwamena et al., 2012; Koh et al., 2008), which recommends the use of explicit and authentic practice opportunities and performance feedback in order to develop patient education self-efficacy and skills (Bosse et al., 2012; Forbes et al., 2018b; Svavarsdóttir et al., 2016). As self-efficacy influences how graduates will engage in clinical practice, opportunities for pre-professional curricula activities targeting this area of practice may enhance proficiency of new graduates in delivering effective patient education (Forbes et al., 2018c).

Lastly, the study findings may have additional implications for enhancing workplace support for new graduates entering the workforce. Social support, feedback and encouragement from workplace colleagues and mentors are factors that positively influence self-efficacy (Bandura, 1997; Van Dinther et al., 2011). As direct vicarious experiences are highlighted as key strategies in both self-efficacy and preparedness for patient education practice, providing mentoring, modeling and observational opportunities in a workplace context may be beneficial. Future research is required, however, to determine the effectiveness of implementing these educational approaches in the workplace and to understand the effect of how training impacts physiotherapy practice.

\section{Strengths and limitations}

The implementation of a mixed-methods design (Creswell \& Clark, 2017) and the timeline of data collection constituted key strengths of the study, permitting comprehensive data collection at point of entry into the workforce and following several months of experience engaging in professional practice (Figure 1). Additional strengths included triangulation of data sources enhancing reliability and employing reflexivity and consensus coding to enhance rigour and trustworthiness of qualitative data, thus accounting for personal bias inherent in qualitative research.

Several limitations of the study must be considered. The adjective "confident", utilised in self-efficacy scale items and the interview framework guide, is not entirely representative of "self-efficacy" as a construct. However, the use of the term "confident" is consistent with self-efficacy scale construction guidelines (Bandura, 1997). Lack of participant familiarity with some survey scale items may have reduced construct validity, and 
social desirability bias and response bias may exist if participants were motivated to answer survey items or interview questions in a socially acceptable manner. Participants were recruited from a single cohort at one Australian tertiary institution, affecting generalisability of findings to new graduates from other regions and institutions. Additionally, participants with low self-efficacy could decline to participate in interviews, resulting in a sample that does not accurately represent the target population, further affecting generalisability. Research team members had a background in physiotherapy training and practice in addition to explicit knowledge of pre-professional curriculum undertaken by participants. This may introduce observer bias and may reduce rigour and transparency. Strategies were implemented to minimise effects, including self and team critical reflection, randomised recruitment for interviews and maintaining relative anonymity of interview participants through use of telephone. Lastly, as the study explored only self-reported practices of physiotherapists, we are unable to report actual clinical behaviours of new graduates that may be captured through other research methods. Observation of clinical practice of physiotherapists is warranted to address how self-reported self-efficacy and preparedness impacts clinical practice behaviours.

\section{Conclusion}

Patient education is fundamental to physiotherapy management and is a clinical competency required for entry-level practice. This study indicates that new graduates have high self-efficacy and perceived preparedness in most aspects of patient education practice; however, they are challenged by perceived barriers to effective practice-in particular, patient-related barriers such as communication, cognition and pre-existing health beliefs. New-graduate physiotherapists relate their development of preparedness for patient education practice to experiential learning experiences and direct clinical practice during their training. These findings highlight that new graduates may require additional training and workplace support to identify, manage and overcome perceived barriers to practice and provide implications for enhancing patient education curricula.

\section{Acknowledgements}

The authors would like to acknowledge the new-graduate physiotherapists who participated within the study.

\section{Funding and conflict of interest statement}

No funding was received for this study, and the authors declare no conflicts of interest.

\section{References}

Ajzen, I. (1991). The theory of planned behavior. Organizational Behavior and Human Decision Processes, 50(2), 179-211. https://doi.org/10.1016/07495978(91)90020-T 
Albaladejo, C., Kovacs, F. M., Royuela, A., del Pino, R., \& Zamora, J. (2010). The efficacy of a short education program and a short physiotherapy program for treating low back pain in primary care: A cluster randomized trial. Spine, 35(5), 483-496. https://doi.org/10.1097/BRS.0b013e3181b9c9a7

Alston, S. D., \& O'Sullivan, T. J. (2005). Patient education in physiotherapy of low back pain: Acute outcomes of group instruction. Irish Journal of Medical Science, 174(3), Article 64. https://doi.org/10.1007/BF03169151

American Physical Therapy Association (APTA). (2016). Standards of practice for physiotherapy. https://www.apta.org/uploadedFiles/APTAorg/About_Us/Policies/ HOD/Practice/Standards.pdf

Bandura, A. (1977). Social learning theory. Prentice Hall.

Bandura, A. (1997). Self-efficacy: The exercise of control. Freeman.

Bartlett, E. (1985). At last, a definition. Patient Education and Counselling, 7(4), 323-324. https://doi.org/10.1016/0738-3991(85)90041-2

Bastable, S. B. (2016). Essentials of patient education. Jones \& Bartlett.

Bosse, H. M., Schultz, J. H., Nickel, M., Lutz, T., Möltner, A., Jünger, J., \&

Nikendei, C. (2012). The effect of using standardized patients or peer role play on ratings of undergraduate communication training: A randomized controlled trial. Patient Education and Counseling, 87(3), 300-306. https://doi.org/10.1016/j. pec.2011.10.007

Cheng, L., Leon, V., Liang, A., Reiher, C., Roberts, D., Feldthusen, C., Mannerkorpi, K., \& Dean, E. (2016). Patient-centered care in physical therapy: Definition, operationalization, and outcome measures. Physical Therapy Reviews, 21(2), 109-123. https://doi.org/10.1080/10833196.2016.1228558

Creswell, J. W. (2014). Research design: Qualitative, quantitative, and mixed methods approaches (4th ed.). Sage.

Creswell, J. W., \& Clark, V. L. P. (2017). Designing and conducting mixed methods research. Sage.

Darkwah, V., Ross, C., Williams, B., \& Madill, H. (2011). Undergraduate nursing student self-efficacy in patient education in a context-based learning program. Journal of Nursing Education, 50(10), 579-582. https://doi. org/10.3928/01484834-20110630-01

Davis, L. A., \& Chesbro, S. B. (2003). Integrating health promotion, patient education, and adult education principles with the older adult: A perspective for rehabilitation professionals. Journal of Allied Health, 32(2), 106-109.

Dwamena, F., Holmes-Rovner, M., Gaulden, C. M., Jorgenson, S., Sadigh, G., Sikorskii, A., Lewin, S., Smith, R. C., Coffey, J., Olomu, A., \& Beasley, M. (2012). Interventions for providers to promote a patient-centred approach in clinical consultations. Cochrane Database of Systematic Reviews. https://doi. org/10.1002/14651858.CD003267.pub2 
Epstein, R. M., \& Street, R. L. (2011). The values and value of patient-centered care. Annals of Family Medicine, 9(2), 100-103. https://doi.org/10.1370/afm.1239

Forbes, R. (2017). Patient education best practice: Enhancing physiotherapy students' selfefficacy and skills [Doctoral thesis, The University of Queensland]. The University of Queensland Digital Archive. https://doi.org/10.14264/uql.2018.93

Forbes, R., Mandrusiak, A., Russell, T., \& Smith, M. (2017). Evaluating physiotherapists' practice and perceptions of patient education: A national survey in Australia. International Journal of Therapy and Rehabilitation, 24(3), 122-130. https://doi.org/10.12968/ijtr.2017.24.3.122

Forbes, R., Mandrusiak, A., Smith, M., \& Russell, T. (2017). A comparison of patient education practices and perceptions of novice and experienced physiotherapists in Australian physiotherapy settings. Musculoskeletal Science and Practice, 28, 46-53. https://doi.org/10.1016/j.msksp.2017.01.007

Forbes, R., Mandrusiak, A., Smith, M., \& Russell, T. (2018a). Identification of competencies for patient education in physiotherapy using a Delphi approach. Physiotherapy, 104(2), 232-238. https://doi.org/10.1016/j.physio.2017.06.002

Forbes, R., Mandrusiak, A., Smith, M., \& Russell, T. (2018b). New-graduate physical therapists' self-efficacy to perform patient education is influenced by entry-level training experiences. Journal of Physical Therapy Education, 32(1), 46-54. https:// doi.org/10.1097/JTE.0000000000000022

Forbes, R., Mandrusiak, A., Smith, M., \& Russell, T. (2018c). Training physiotherapy students to educate patients: A randomised controlled trial. Patient Education and Counseling, 101(2), 295-303. https://doi.org/10.1016/j.pec.2017.08.009

Glanz, K., Rimer, B. K., \& Viswanath, K. (2008). Theory, research, and practice in health behavior and health education (4th ed.). Jossey-Bass.

Gould, E., \& Mitty, E. (2010). Medication adherence is a partnership, medication compliance is not. Geriatric Nursing, 31(4), 290-298. https://doi.org/10.1016/j. gerinurse.2010.05.004

Hiller, A., Guillemin, M., \& Delany, C. (2015). Exploring healthcare communication models in private physiotherapy practice. Patient Education and Counseling, 98(10), 1222-1228. https://doi.org/10.1016/j.pec.2015.07.029

Hojat, M., Vergare, M. J., Maxwell, K., Brainard, G., Herrine, S. K., Isenberg, G. A., Veloski, J., \& Gonnella, J. S. (2009). The devil is in the third year: A longitudinal study of erosion of empathy in medical school. Academic Medicine, 84(9), 11821191. https://doi.org/10.1097/ACM.0b013e3181b17e55

Holmes, C. (1999). The attitudes and perspectives of physical therapist students regarding patient education. Journal of Physical Therapy Education, 13(2), 8-16.

Hyrkas, K., \& Wiggins, M. (2014). A comparison of usual care, a patient-centred education intervention and motivational interviewing to improve medication adherence and readmissions of adults in an acute-care setting. Journal of Nursing Management, 22(3), 350-361. https://doi.org/10.1111/jonm.12221 
Jensen, G. M., Gwyer, J., Shepard, K. F., \& Hack, L. M. (2000). Expert practice in physical therapy. Physical Therapy, 80(1), 28-43. https://doi.org/10.1093/ ptj/80.1.28

Jensen, G. M., Shepard, K. F., \& Hack, L. M. (1990). The novice versus the experienced clinician: Insights into the work of the physical therapist. Physical Therapy, 70(5), 314-323. https://doi.org/10.1093/ptj/70.5.314

Jette, D. U., Latham, N. K., Smout, R. J., Gassaway, J., Slavin, M. D., \& Horn, S. D. (2005). Physical therapy interventions for patients with stroke in inpatient rehabilitation facilities. Physical Therapy, 85(3), 238-248. https://doi.org/10.1093/ $\mathrm{ptj} / 85.3 .238$

Jones, A., \& Sheppard, L. (2011). Self-efficacy and clinical performance: A physiotherapy example. Advances in Physiotherapy, 13(2), 79-83. https://doi.org/1 $0.3109 / 14038196.2011 .565072$

Kerssens, J. J., Sluijs, E. M., Verhaak, P. F., Knibbe, H. J., \& Hermans, I. M. (1999). Back care instructions in physical therapy: A trend analysis of individualized back care programs. Physical Therapy, 79(3), 286-295. https://doi.org/10.1093/ $\mathrm{ptj} / 79.3 .286$

King, A., \& Hoppe, R. B. (2013). "Best practice" for patient-centered communication: A narrative review. Journal of Graduate Medical Education, 5(3), 385-393. https://doi.org/10.4300/JGME-D-13-00072.1

Koh, G. C. H., Khoo, H. E., Wong, M. L., \& Koh, D. (2008). The effects of problem-based learning during medical school on physician competency: A systematic review. CMAJ, 178(1), 34-41. https://doi.org/10.1503/cmaj.070565

Lagger, G., Pataky, Z., \& Golay, A. (2010). Efficacy of therapeutic patient education in chronic diseases and obesity. Patient Education and Counseling, 79(3), 283-286. https://doi.org/10.1016/j.pec.2010.03.015

Levinson, W., Lesser, C. S., \& Epstein, R. M. (2010). Developing physician communication skills for patient-centered care. Health Affairs, 29(7), 1310-1318. https://doi.org/10.1377/hlthaff.2009.0450

Little, P., Everitt, H., Williamson, I., Warner, G., Moore, M., Gould, C., Ferrier, K., \& Payne, S. (2001). Preferences of patients for patient centred approach to consultation in primary care: Observational study. BMJ, 322(7284), 468-472. https://doi.org/10.1136/bmj.322.7284.468

Louw, A., Diener, I., Butler, D. S., \& Puentedura, E. J. (2011). The effect of neuroscience education on pain, disability, anxiety, and stress in chronic musculoskeletal pain. Archives of Physical Medicine and Rehabilitation, 92(12), 2041-2056. https://doi.org/10.1016/j.apmr.2011.07.198

Mays, N., \& Pope, C. (2000). Assessing quality in qualitative research. BMJ, 320(7226), 50-52. https://doi.org/10.1136/bmj.320.7226.50

Moustakas, C. (1994). Phenomenological research methods. Sage. 
Ndosi, M., Johnson, D., Young, T., Hardware, B., Hill, J., Maxwell, J., Roussou, E., \& Adebajo, A. (2015). Effects of needs-based patient education on self-efficacy and health outcomes in people with rheumatoid arthritis: A multicentre, single blind, randomised controlled trial. Annals of the Rheumatic Diseases, 75(6), 11261132. https://doi.org/10.1136/annrheumdis-2014-207171

Nour, K., Laforest, S., Gauvin, L., \& Gignac, M. (2006). Behavior change following a self-management intervention for housebound older adults with arthritis: An experimental study. International Journal of Behavioral Nutrition and Physical Activity, 3, Article 12. https://doi.org/10.1186/1479-5868-3-12

Nunez, M., Nunez, E., Yoldi, C., Quinto, L., Hernandez, M.V., \& Munoz-Gomez, J. (2006). Health-related quality of life in rheumatoid arthritis: Therapeutic education plus pharmacological treatment versus pharmacological treatment only. Rheumatology International, 26(8), 752-757. https://doi.org/10.1007/s00296005-0071-6.

Physiotherapy Board of Australia (PBA) and Physiotherapy Board of Zealand (PBNZ). (2015). Physiotherapy practice thresholds in Australia and Aotearoa New Zealand. https://physiocouncil.com.au/wp-content/uploads/2017/10/ Physiotherapy-Board-Physiotherapy-practice-thresholds-in-Australia-andAotearoa-New-Zealand.pdf

Pinto, R. Z., Ferreira, M. L., Oliveira, V. C., Franco, M. R., Adams, R., Maher, C. G., \& Ferreira, P. H. (2012). Patient-centred communication is associated with positive therapeutic alliance: A systematic review. Journal of Physiotherapy, 58(2), 77-87. https://doi.org/10.1016/S1836-9553(12)70087-5

Resnik, L., \& Jensen, G. M. (2003). Using clinical outcomes to explore the theory of expert practice in physical therapy. Physical Therapy, 83(12), 1090-1106. https:// doi.org/10.1093/ptj/83.12.1090

Ross, E. F., \& Haidet, P. (2011). Attitudes of physical therapy students toward patient-centered care, before and after a course in psychosocial aspects of care. Patient Education and Counseling, 85(3), 529-532. https://doi.org/10.1016/j. pec.2011.01.034

Sanders, T., Foster, N. E., Bishop, A., \& Ong, B. N. (2013). Biopsychosocial care and the physiotherapy encounter: Physiotherapists' accounts of back pain consultations. BMC Musculoskeletal Disorders, 14(1), Article 65. https://doi. org/10.1186/1471-2474-14-65

Skelton, A. (2001). Evolution not revolution? The struggle for the recognition and development of patient education in the UK. Patient Education and Counseling, 44(1), 23-27. https://doi.org/10.1016/S0738-3991(01)00098-2

Slade, S. C., Molloy, E., \& Keating, J. L. (2012). The dilemma of diagnostic uncertainty when treating people with chronic low back pain: A qualitative study. Clinical Rehabilitation, 26(6), 558-569. https://doi. org/10.1177/0269215511420179 
Sluijs, E. M., van der Zee, J., \& Kok, G. J. (1993). Differences between physical therapists in attention paid to patient education. Physiotherapy Theory and Practice, 9(2), 103-118. https://doi.org/10.3109/09593989309052922

Svavarsdóttir, M. H., Sigurðardóttir, Á. K., \& Steinsbekk, A. (2015). How to become an expert educator: A qualitative study on the view of health professionals with experience in patient education. BMC Medical Education, 15(1), Article 87. https://doi.org/10.1186/s12909-015-0370-x

Svavarsdóttir, M. H., Sigurðardóttir, Á. K., \& Steinsbekk, A. (2016). Knowledge and skills needed for patient education for individuals with coronary heart disease: The perspective of health professionals. European Journal of Cardiovascular Nursing, 15(1), 55-63. https://doi.org/10.1177/1474515114551123

Van Dinther, M., Dochy, F., \& Segers, M. (2011). Factors affecting students' selfefficacy in higher education. Educational Research Review, 6(2), 95-108. https:// doi.org/10.1016/j.edurev.2010.10.003 